\title{
Overview of Permanent-Magnet Brushless Drives for Electric and Hybrid Electric Vehicles
}

\author{
K. T. Chau, Senior Member, IEEE, C. C. Chan, Fellow, IEEE, and Chunhua Liu, Student Member, IEEE
}

\begin{abstract}
With ever-increasing concerns on our environment, there is a fast growing interest in electric vehicles (EVs) and hybrid EVs (HEVs) from automakers, governments, and customers. As electric drives are the core of both EVs and HEVs, it is a pressing need for researchers to develop advanced electric-drive systems. In this paper, an overview of permanent-magnet (PM) brushless (BL) drives for EVs and HEVs is presented, with emphasis on machine topologies, drive operations, and control strategies. Then, three major research directions of the PM BL drive systems are elaborated, namely, the magnetic-geared outer-rotor PM BL drive system, the PM BL integrated starter-generator system, and the PM BL electric variable-transmission system.
\end{abstract}

Index Terms-Electric variable transmission (EVT), electric vehicle (EV), hybrid EV (HEV), integrated starter generator (ISG), magnetic gear, permanent-magnet (PM) brushless (BL) drives.

\section{INTRODUCTION}

$\mathbf{V}$ EHICLES equipped with internal combustion engine (ICE) have been in existence for over a hundred years. Although ICE vehicles (ICEVs) are being improved by modern automotive electronics technology, they need a major change to significantly improve the fuel economy and reduce the emissions. Electric vehicles (EVs) and hybrid EVs (HEVs) have been identified to be the most viable solutions to fundamentally solve the problems associated with ICEVs [1]-[3].

Electric drives are the core technology for EVs and HEVs. The basic characteristics of an electric drive for EVs are the following [4]-[6]:

1) high torque density and power density;

2) very wide speed range, covering low-speed crawling and high-speed cruising;

3) high efficiency over wide torque and speed ranges;

4) wide constant-power operating capability;

5) high torque capability for electric launch and hill climbing;

6) high intermittent overload capability for overtaking;

7) high reliability and robustness for vehicular environment;

Manuscript received April 30, 2007; revised December 5, 2007. This work was supported by the Research Grants Council, Hong Kong Special Administrative Region, China, under Grant HKU 7105/07E

The authors are with the International Research Center for Electric Vehicles, Department of Electrical and Electronic Engineering, The University of Hong Kong, Hong Kong, China (e-mail: ktchau@eee.hku.hk; ccchan@eee. hku.hk; chualiu@eee.hku.hk).

Digital Object Identifier 10.1109/TIE.2007.918403

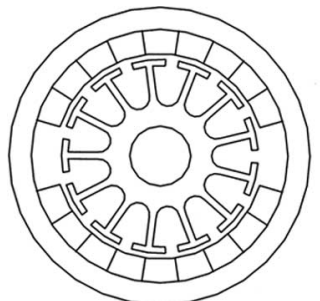

(a)

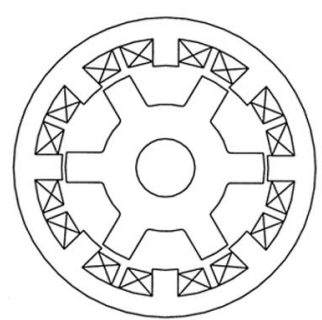

(c)

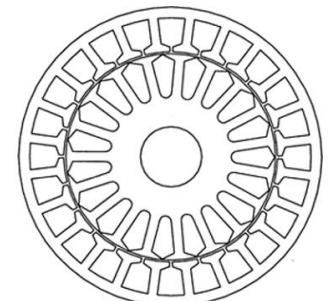

(b)

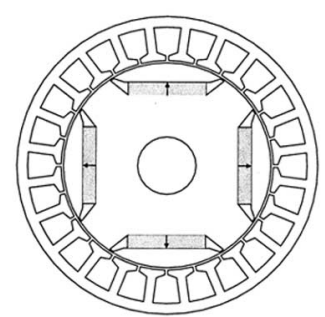

(d)
Fig. 1. Major EV machine topologies. (a) DC. (b) Induction. (c) SR. (d) PM BL.

8) low acoustic noise;

9) reasonable cost.

On top of the aforementioned characteristics, the electric drive for HEVs needs additional ones as follows [7]-[9]:

1) high-efficiency generation over a wide speed range;

2) good voltage regulation over wide-speed generation

With the advent of high-energy permanent-magnet (PM) materials, PM motors are becoming more and more attractive. Being continually fueled by new machine topologies and control strategies, PM brushless (BL) drives have been identified to be the most promising to provide the aforementioned characteristics for modern EVs and HEVs [10].

The purpose of this paper is to give an overview of the PM BL drives for EVs and HEVs. Thus, the state-of-the-art technology of PM BL drive systems, including their machine topologies, drive operations, control strategies, and emerging research directions, will be reviewed and discussed.

In Section II, the classification of various EV drives, namely, dc, induction, switched reluctance (SR), and PM BL ones, will be described. In focusing on the PM BL drives, various machine topologies, drive operations, and control strategies will be discussed in Sections III-V, respectively. In Section VI, the latest research directions of the PM BL drive systems for EVs and HEVs will be identified and discussed in detail. Finally, a conclusion is drawn in Section VII. 


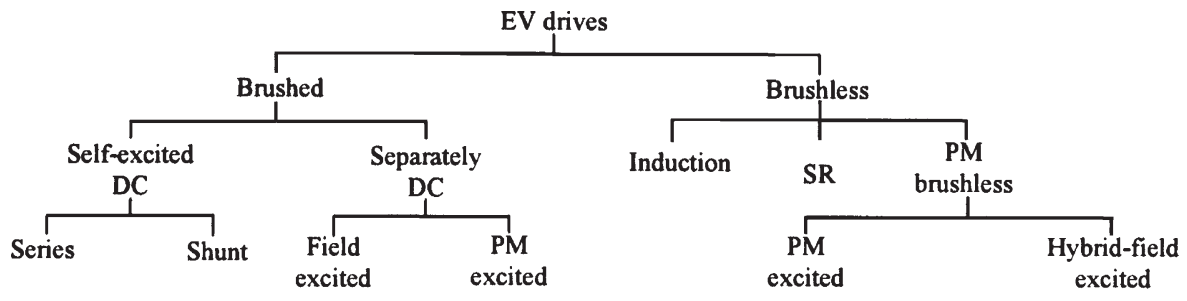

Fig. 2. Classification of the EV drives.

\section{Classification of EV Drives}

Among different types of electric drives, there are four major types that are viable for EVs, namely, dc, induction, SR, and PM BL drives. They possess fundamentally different machine topologies, as shown in Fig. 1. Basically, they are classified into two main groups, namely, the brushed and the brushless, and each group can be further classified into different subgroups, as shown in Fig. 2. It should be noted that the branches that are not viable for EVs have been pruned. Table I also lists the previous or latest applications of those viable EV drives to flagship EVs.

DC drives are used to be widely accepted for EVs. Because of the orthogonal disposition of field and armature MMFs, dc drives take the definite advantage of simple control. By replacing the field winding with PMs, the PM dc drives permit a considerable reduction in stator diameter due to the efficient use of radial space. Owing to the low permeability of PMs, armature reaction is usually reduced, and commutation is improved. However, the principle problem of dc drives, due to their commutators and brushes, makes them less reliable and unsuitable for a maintenance-free operation.

Induction drives are a widely accepted brushless drive for EVs because of their low cost, high reliability, and freedom from maintenance. However, conventional control of induction drives, such as variable voltage variable frequency, cannot provide the desired performance. The major reason is due to the nonlinearities of their dynamic model. With the advent of microcomputer era, the principle of field-oriented control or vector control of induction drives has been accepted to overcome their nonlinearities. Moreover, the development of $\mathrm{EV}$ induction drives is continually fueled by new design approaches and advanced control strategies. Recently, new design approaches have been developed to improve the power density of EV induction drives by up to $30 \%$ [11]. Interdisciplinary design considerations on mechanical vibration and acoustic noise of induction drives have also been analyzed for EVs [12]. On the other hand, efficiency-optimizing-control (EOC) approaches have been developed for the EV induction drives, which can reduce the consumed energy by about $10 \%$ and increase the regenerative energy by about $4 \%$, leading to the extension of the driving range of EVs by more than $14 \%$ [13]. In addition, electrically pole-changing schemes have been developed for the EV induction drives, which can significantly extend the constant-power operating region to over four times the base speed [14].

SR drives have been recognized to have a considerable potential for EVs. They have the definite advantages of simple construction, low manufacturing cost, and outstanding torquespeed characteristics. Although they possess simplicity in con-
TABLE I

APPLICATIONS OF EV DRIVES TO EVs

\begin{tabular}{ll}
\hline EV models & EV drives \\
\hline Fiat Panda Elettra & Series DC drive \\
Mazda Bongo & Shunt DC drive \\
Conceptor G-Van & Separately excited DC drive \\
Suzuki Senior Tricycle & PM DC drive \\
GM EV1 & Induction drive \\
Toyota Prius & PM brushless drive \\
Chloride Lucas & SR drive \\
\hline
\end{tabular}

struction, their design and control are difficult and subtle. In addition, they usually exhibit acoustic-noise problems. Recently, fuzzy sliding mode control has been developed for the EV SR drives so as to handle the machine nonlinearities and minimize the control chattering [15]. In addition, the corresponding constant-power region has been extended to three to seven times the base speed through phase advancing excitation [16], [17]. On the other hand, an active vibration cancellation technique for the SR drives has been proposed, which induces an antiphase vibration to cancel a specified vibration mode and, hence, reduces the acoustic noise [18].

PM BL drives are becoming more and more attractive and can directly compete with the induction drives for EVs. The definite advantages of PM BL drives are their inherently high efficiency, high power density, and high reliability. The key problem is their relatively high cost due to PM materials. In general, according to the operating current and no-load electromotive-force (EMF) waveforms, they are classified as PM BL ac (BLAC) and PM BL dc (BLDC) types [19]. In recent years, the class of PM BL drives has been expanded to embrace those with hybrid field excitations.

\section{PM BL MACHINE TOPOLOGIES}

\section{A. PM BL Machine Morphologies}

According to the directions of magnetic flux paths and current-carrying conductors, all electric machine topologies can generally be represented as radial-field, axial-field, and linear-field morphologies. Thus, all PM BL machine topologies can have different morphological representations, as shown in Fig. 3(a)-(c). In the following, the discussion will be based on the radial-field morphology, which can readily be extended to other morphologies.

It should be noted that some machine topologies, such as the transverse-flux PM BL drive, cannot be classified into the aforementioned three basic morphologies. Its flux path is $3 \mathrm{D}$, involving radial, axial, and circumferential directions, as shown in Fig. 3(d). 


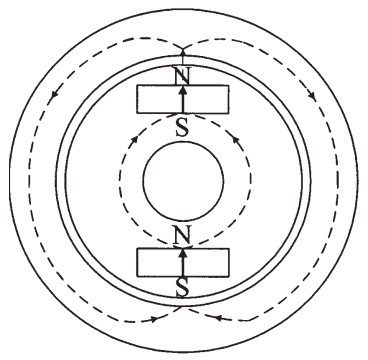

(a)

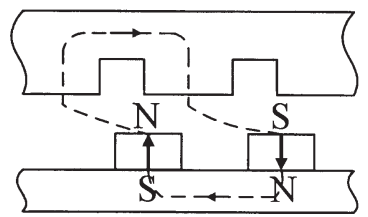

(c)

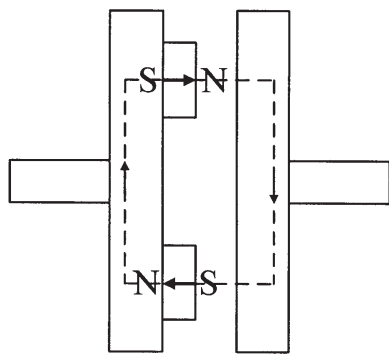

(b)

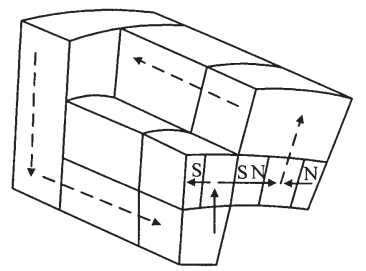

(d)
Fig. 3. PM BL machine morphologies. (a) Radial field. (b) Axial field. (c) Linear field. (d) Transverse flux.

\section{B. Rotor PM BL Machine Topologies}

The rotor PM BL topologies are most popular. According to the position of PMs in the rotor [5], [19], they can further be classified as surface-mounted, surface-inset, interior-radial, and interior-circumferential topologies, as shown in Fig. 4.

The generated torque of these rotor PM BL machines consists of two components, namely, the PM torque and the reluctance torque, which are given by

$$
T=\frac{3}{2} p\left[\psi_{\mathrm{m}} I_{q}-\left(L_{q}-L_{d}\right) I_{d} I_{q}\right]
$$

where $p$ is the number of pole pairs, $\psi_{\mathrm{m}}$ is the stator winding flux linkage due to the PMs, $L_{d}$ and $L_{q}$ are the $d$-and $q$-axis stator winding inductances, respectively, and $I_{d}$ and $I_{q}$ are the $d$ - and $q$-axis currents, respectively.

For the surface-mounted PM BL machine topology, as shown in Fig. 4(a), the PMs are simply mounted on the rotor surface by using epoxy adhesives. Since the permeability of PMs is near to that of air, the effective airgap is the sum of the actual airgap length and the radial thickness of the PMs. Hence, the corresponding armature-reaction field is small, and the stator winding inductance is low. In addition, since the $d$ - and $q$-axis stator winding inductances are nearly the same, its reluctance torque is almost zero. For the surface-inset PM BL machine topology, as shown in Fig. 4(b), the PMs are inset into the rotor surface. Thus, the $q$-axis inductance becomes higher than the $d$-axis inductance, hence producing the reluctance torque.

For the interior-radial PM BL machine topology, as shown in Fig. 4(c), the PMs are radially magnetized and buried inside the rotor. Since the PMs are mechanically protected, it allows for a high-speed operation. In addition, because of its $d-q$ saliency, a reluctance torque exists. For the interior-circumferential PM BL machine topology, as shown in Fig. 4(d), the PMs are circumferentially magnetized and buried inside the rotor. It takes the definite advantage that the airgap flux density can be higher than the PM flux density, which is the so-called flux focusing.

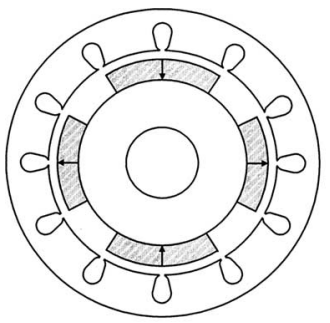

(a)

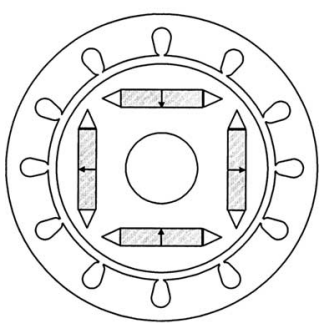

(c)

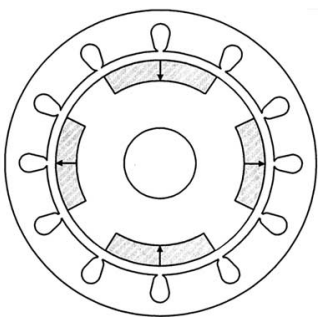

(b)

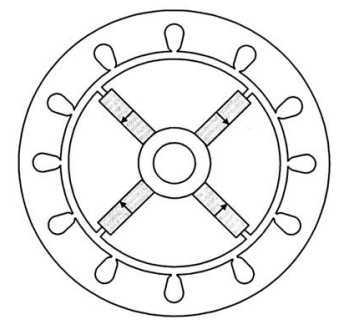

(d)
Fig. 4. Rotor PM BL machine topologies. (a) Surface mounted. (b) Surface inset. (c) Interior radial. (d) Interior circumferential.

\section{Stator PM BL Machine Topologies}

The stator PM BL machine topologies are with PMs located in the stator and generally with salient poles in both the stator and the rotor. Thus, they are usually termed as doubly salient PM (DSPM) machines. Since the rotor has neither PMs nor windings, these DSPM machines are mechanically simple and robust, hence very suitable for high-speed operation. According to the shape and location of the PMs, they can be classified as the yoke-linear-magnet, yoke-curved-magnet, tooth-surface-magnet, and tooth-interior-magnet machines, as shown in Fig. 5.

As shown in Fig. 5(a), the yoke-linear-magnet machine topology is commonly adopted in the DSPM machines [20]-[22]. Although they are salient poles in the stator and the rotor, the PM torque significantly dominates the reluctance torque, hence exhibiting low cogging torque. Since the variation of the flux linkage with each coil as the rotor rotates is unipolar, it is very suitable for the BLDC operation. On the other hand, when the rotor is skewed, it can offer the BLAC operation. The major disadvantage of this topology is the relatively low torque density, as resulted from its unipolar flux linkage.

As shown in Fig. 5(b), the yoke-curved-magnet machine topology is very similar to the previous one, except the shape of PMs. Since there is more space to accommodate the PMs, this DSPM machine can achieve a higher airgap flux density. Its major drawback is the difficulty in machining the curved PMs.

The tooth-surface-magnet machine topology shown in Fig. 5(c) is commonly termed as the flux-reversal PM machine since the flux linkage with each coil reverses polarity as the rotor rotates [23]. Each stator tooth has a pair of PMs of different polarities mounted onto the surface. Hence, the fluxlinkage variation is bipolar so that the torque density is higher than that of the conventional DSPM machine. However, since the PMs are on the surface of stator teeth, they are more prone to partial demagnetization. In addition, significant eddy current loss in the PMs may be resulted. 


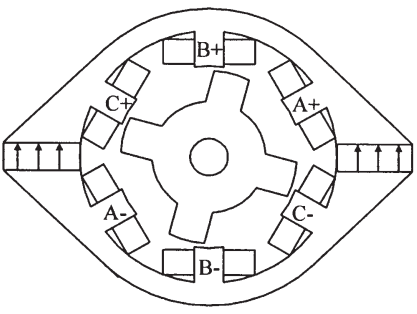

(a)

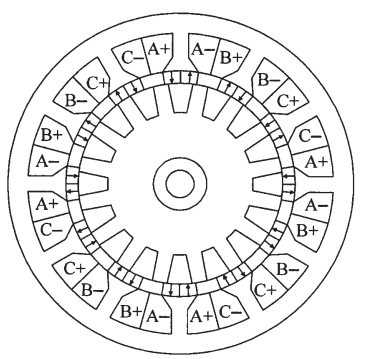

(c)

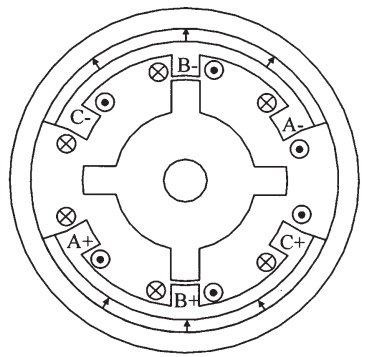

(b)

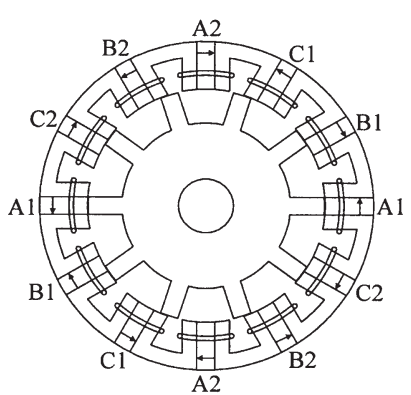

(d)
Fig. 5. Stator PM BL machine topologies. (a) Yoke linear magnet. (b) Yoke curved magnet. (c) Tooth surface magnet. (d) Tooth interior magnet.

The tooth-interior-magnet machine topology shown in Fig. 5(d) is commonly termed as the flux-switching PM machine [24]. In this topology, each stator tooth consists of two adjacent laminated segments and a PM, and each of these segments is sandwiched by two circumferentially magnetized PMs. Hence, it enables flux focusing. Compared with the rotor PM topologies, this flux-switching machine has less armature reaction, hence offering higher electric loading. Since its back EMF waveform is essentially sinusoidal, this machine is more suitable for the BLAC operation.

\section{Hybrid PM BL Machine Topologies}

In general, these hybrid PM BL machine topologies are referred to the machines that the PM excitation is hybridized with the dc field winding excitation to produce a magnetic field. There are many attractive features due to the presence of the hybrid PM field.

1) By varying the polarity and magnitude of the dc field winding current, the airgap flux density becomes easily controllable.

2) By realizing flux strengthening, the machine can offer the exceptionally high-torque feature, which is very essential for cold cranking HEVs or providing temporary power for vehicular overtaking and hill climbing.

3) By realizing flux weakening, the machine can offer the exceptionally wide-speed constant-power feature, which is very essential for $\mathrm{EV}$ cruising.

4) By online tuning the airgap flux density, the machine can maintain a constant voltage output under generation or regeneration over a very wide speed range, which is very essential for battery charging various EVs.

5) By online tuning the airgap flux density, the machine can also offer EOC, which is highly desirable for EVs.

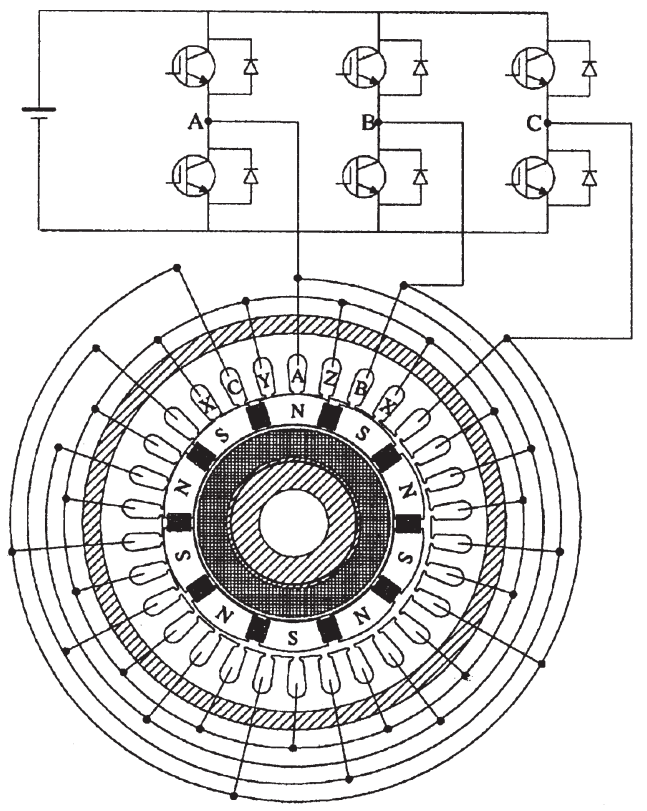

(a)

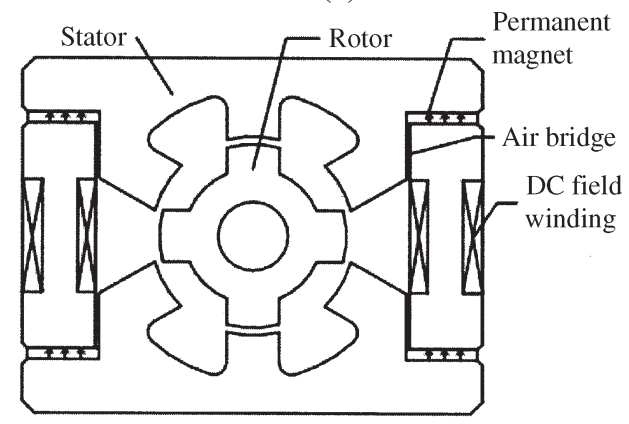

(b)

Fig. 6. Hybrid PM BL machine topologies. (a) Double-stator doubly fed. (b) Stator doubly fed doubly salient.

Fig. 6(a) shows the configuration of a double-stator clawtype-rotor doubly fed hybrid PM machine which is specially designed for EVs [10]. This machine topology takes the advantages of compact structure and effective flux control. By tuning the dc field winding current in the inner stator, it can achieve a very wide speed range of constant-power operation and online efficiency optimization. On the other hand, Fig. 6(b) shows another type of hybrid PM machines, in which both the PMs and the dc field windings are located in the same stator [25], [26]. Hence, this stator doubly fed doubly salient configuration is relatively simpler, but with the tradeoff of higher leakage flux.

\section{E. Memory PM BL Machine Topologies}

The memory PM BL machine is a new class of fluxcontrollable PM machines, which has the distinct ability to change the intensity of magnetization and also memorize the flux-density level in the PMs [27]. As shown in Fig. 7, this topology consists of Alnico PMs sandwiched by soft iron, which are then mechanically fixed to a nonmagnetic shaft. The online magnetization is achieved by properly applying a short dc current pulse flowing through the stator armature 


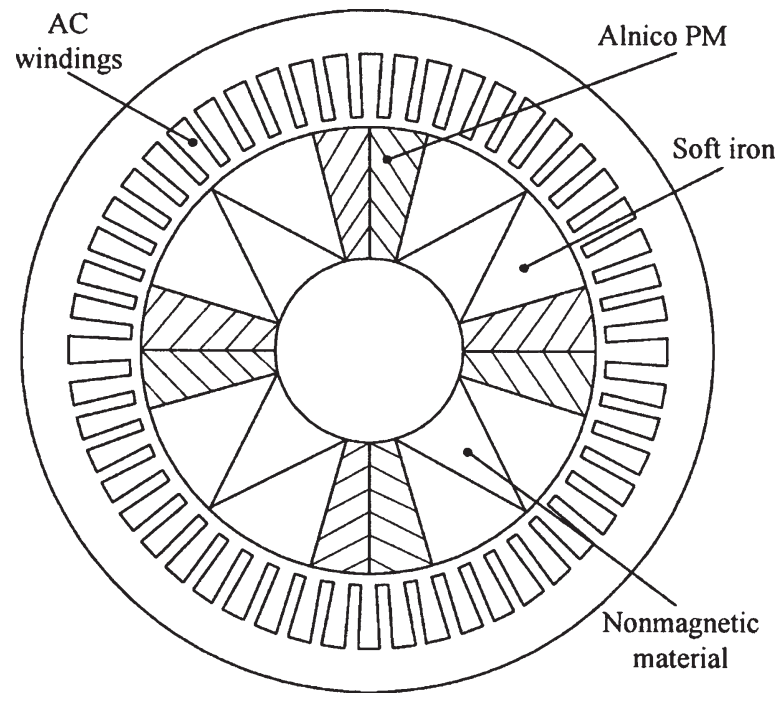

Fig. 7. Memory PM BL machine topology.

TABLE II

COMPARISON OF MACHINE TOPOLOGIES

\begin{tabular}{lllll}
\hline & Rotor-PM & Stator-PM & Hybrid-PM & Memory-PM \\
\hline PM material & Nd-Fe-B & Nd-Fe-B & Nd-Fe-B & Alnico \\
Excitations & PMs only & PMs only & $\begin{array}{l}\text { PMs and } \\
\text { windings }\end{array}$ & PMs only \\
& & & & \\
Flux control & Complex & Complex & Easy & Medium \\
Efficiency & Very high & Very high & High & High \\
Power density & Very high & Very high & High & High \\
Speed range & Wide & Wide & Very wide & Very wide \\
Overload ability Good & Good & Very good & Fair \\
Reliability & Reliable & Very reliable Reliable & Less reliable \\
Maturity & Very mature Developing & Developing & Immature \\
\hline
\end{tabular}

winding to change the magnetization level of the Alnico PMs in the rotor.

\section{F. Comparison of Machine Topologies}

The aforementioned PM BL machines with the radial-field morphology are compared, as shown in Table II. This comparison is focused on assessing some key features for EV drives, namely efficiency, power density, speed range, overloadability, reliability, and maturity.

\section{PM BL DRIVE OPERATIONS}

\section{A. BLAC and BLDC Operations}

As aforementioned, the PM BL drives have two basic operations, namely, the BLAC and the BLDC, as shown in Fig. 8. Each PM BL machine can operate at both modes if the torque density, torque smoothness, and efficiency are not highly concerned.

For the PM BLAC drives, they operate with sinusoidal current and sinusoidal airgap flux so that they need a highresolution position signal for closed-loop control, hence desiring a costly position encoder or resolver. On the other hand, for the PM BLDC drives, they operate with a rectangular current and a trapezoidal airgap flux so that they just need a low-cost sensor for phase-current commutation.

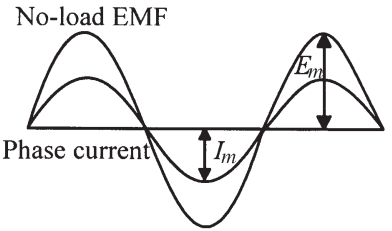

(a)

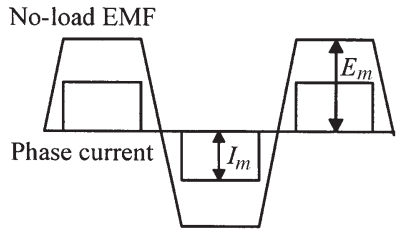

(b)
Fig. 8. Theoretical waveforms of PM BL operations. (a) BLAC. (b) BLDC.

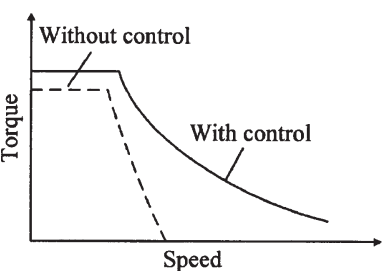

(a) (b)

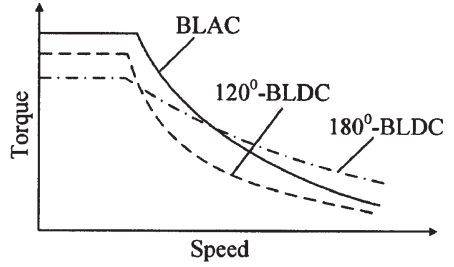

Fig. 9. Torque-speed characteristics of the PM BL drives. (a) With and without control. (b) BLAC versus BLDC.

\section{B. Constant-Power Operation}

EV drives desire to operate over a very wide speed range, particularly high-speed constant-power operation for cruising. Different types of PM BL drives may adopt different methods for constant-power operation.

For the PM BLAC drives, constant-power operation can readily be offered by using flux-weakening control. The maximum flux-weakening capability is achieved when the machine is designed to have a unity per-unit $d$-axis inductance [28]

$$
\frac{L_{d} I_{\mathrm{r}}}{\psi_{\mathrm{m}}}=1
$$

where $I_{\mathrm{r}}$ is the rated current. In general, the ratio of $L_{d} I_{\mathrm{r}} / \psi_{\mathrm{m}}$ is less than unity. Thus, the higher the ratio, the higher the flux-weakening capability. The flux-weakening control has been comprehensively studied in various PM BLAC drives [29], [30].

For the PM BLDC drives, constant-power operation is more complex. Since the operating waveforms are no longer sinusoidal, $d-q$ transformation and, hence, flux-weakening control are ill suited. Nevertheless, the corresponding constant-power operation can be offered by using advanced conduction angle control [31], [32].

Fig. 9(a) shows the torque-speed characteristics of the PM BL drives with and without control (flux-weakening control or advanced conduction angle control). It illustrates that the speed range of constant-power operation can be significantly extended. On the other hand, Fig. 9(b) shows a comparison of the torque-speed characteristics of the PM BLAC and the PM BLDC drives. It can be seen that the BLAC drive offers higher torque and power capabilities than the BLDC drive, employing a two-phase $120^{\circ}$ conduction. Nevertheless, the BLDC drive employing a three-phase $180^{\circ}$ conduction can offer a better high-speed power capability, but with the sacrifice of low-speed torque capability [5].

Moreover, for the PM BLDC drive with multiphase polygonal windings [33], the corresponding back EMF, rather than 
the airgap flux, can be directly varied to enable constant-power operation. Similarly, the split-winding DSPM drive [34] can perform a constant-power operation by varying the effective number of armature-winding turns. For those hybrid PM BL drives, including the BLAC [10] or BLDC [25], [26] types, the airgap flux can be easily controlled by varying the polarity and magnitude of the dc field current, hence achieving a constantpower operation.

\section{PM BL Drive Control Strategies}

\section{A. $E O C$}

EOC of the PM BL drives is highly desirable for EVs since their on-board energy storage is very limited. Different types of PM BL drives may employ different ways for efficiency optimization.

For the rotor PM BLAC drives, the EOC can be achieved by online tuning the input voltage or the $d$-axis armature current $I_{2 d}$ to minimize the total losses $P_{\text {loss }}$ [35], [36]

$$
P_{\text {loss }}\left(I_{2 d}, T, \omega\right)=P_{\mathrm{Cu}}\left(I_{2 d}, T, \omega\right)+P_{\mathrm{Fe}}\left(I_{2 d}, T, \omega\right)
$$

where $P_{\mathrm{Cu}}$ is the copper loss, and $P_{\mathrm{Fe}}$ is the iron loss for the given torque $T$ and speed $\omega$. It can be found that there is a unique optimal operating point. In particular, the minimum total losses occur at a lower $d$-axis armature current than that of the minimum copper loss, hence illustrating that the maximum torque per ampere control cannot maximize the efficiency of the PM BLAC drives. For the hybrid PM BLAC drive incorporating with an additional dc field winding [10], the EOC can be easily achieved by tuning the polarity and magnitude of the dc field current.

\section{B. Direct Torque Control}

Direct torque control (DTC) is becoming attractive for EVs, particularly for those equipped with dual-motor propulsion which desires fast torque response. It does not rely on current control and less depends on parameters. For the PM BLAC drives, the DTC controls both the torque and the flux linkage independently [37], [38]. The controller outputs provide proper voltage vectors via the inverter in such a way that these two variables are forced to predefined trajectories.

\section{Artificial Intelligent Control}

All artificial-intelligence-based control strategies, such as fuzzy logic control, neural network control, neuro-fuzzy control, and genetic control, are classified as artificial intelligent control (AIC). Among them, the fuzzy logic control [39] and the neural network control [40] are most mature and attractive for the PM BL drives since they can effectively handle the system's nonlinearities and sensitivities to parameter variations.

\section{Position-Sensorless Control}

In order to achieve high performance for EV drives, position feedback is almost mandatory. In order to get rid of the costly and bulky position encoder, position-sensorless control (PSC)
TABLE III

COMPARISON OF CONTROL STRATEGIES

\begin{tabular}{|c|c|c|c|}
\hline & Advantages & Disadvantages & Techniques \\
\hline EOC & $\begin{array}{l}\text { Minimize the overall } \\
\text { losses; no need for } \\
\text { accurate loss model; } \\
\text { work for wide speed } \\
\text { and torque ranges }\end{array}$ & $\begin{array}{l}\text { Originate system } \\
\text { oscillation or } \\
\text { convergence problem }\end{array}$ & $\begin{array}{l}\text { Control the input } \\
\text { voltage or d-axis } \\
\text { armature current; } \\
\text { control DC field } \\
\text { current. }\end{array}$ \\
\hline DTC & $\begin{array}{l}\text { Fast torque response; } \\
\text { no need for current } \\
\text { control; less } \\
\text { parameter } \\
\text { dependence }\end{array}$ & $\begin{array}{l}\text { Cause errors due to } \\
\text { drift in stator flux } \\
\text { linkage estimation, } \\
\text { and variation of } \\
\text { stator resistance }\end{array}$ & $\begin{array}{l}\text { Generate the voltage } \\
\text { vectors using } \\
\text { independent torque } \\
\text { and flux } \\
\text { computations }\end{array}$ \\
\hline AIC & $\begin{array}{l}\text { Flexible control } \\
\text { algorithms; adapt } \\
\text { nonlinearities and } \\
\text { parameter variations }\end{array}$ & $\begin{array}{l}\text { Require expert } \\
\text { knowledge, or } \\
\text { intensive } \\
\text { computation and } \\
\text { sophisticated } \\
\text { hardware }\end{array}$ & $\begin{array}{l}\text { Incorporate fuzzy } \\
\text { logic, neural } \\
\text { network, or other AI } \\
\text { into traditional } \\
\text { controls }\end{array}$ \\
\hline PSC & $\begin{array}{l}\text { Eliminate the } \\
\text { position sensor, } \\
\text { hence reducing the } \\
\text { system size and cost; } \\
\text { readily merge into } \\
\text { other controls }\end{array}$ & $\begin{array}{l}\text { Require intensive } \\
\text { computation and } \\
\text { sophisticated } \\
\text { hardware }\end{array}$ & $\begin{array}{l}\text { Estimate the } \\
\text { position based on } \\
\text { the motional EMF, } \\
\text { inductance } \\
\text { variation, or flux } \\
\text { linkage variation }\end{array}$ \\
\hline
\end{tabular}

is becoming attractive [41]-[43]. There are various PSC techniques which can be classified as motional EMF, inductance variation, and flux-linkage variation. Basically, the position information is derived by online analysis of the voltages and currents in the machine windings.

It should be noted that the PSC can be readily incorporated into other control strategies such as the EOC, the DTC, and the AIC.

\section{E. Comparison of Control Strategies}

As shown in Table III, the aforementioned control strategies are compared in terms of their major advantages, major disadvantages, and typical techniques. Since there are many possible strategies for the AIC, the self-tuning fuzzy PI control [39] is used for exemplification. The corresponding control block diagrams are shown in Fig. 10. Finally, some sample results of these control strategies are shown in Fig. 11 which illustrates that the EOC can achieve the minimum total losses [36], the DTC can provide direct bang-bang control of torque [38], the AIC can achieve fast and accurate response [39], and the PSC can offer accurate estimation of rotor position [42].

\section{INTEGRATIVE TECHNOLOGIES}

In recent years, the development of EVs and HEVs has been focused on two themes, namely, the new energy sources and the propulsion systems. In particular, the development of propulsion systems is no longer limited to the design and operation of a single machine or drive. The current research direction is system integration for propulsion. In the following, three emerging integrative technologies are identified and discussed, namely, the integration of magnetic gearing and PM BL drives for EVs, the integration of PM BL starter motors and generators for micro- and mild HEVs, and the integration of PM BL drives and electric variable transmission (EVT) for full HEVs. 


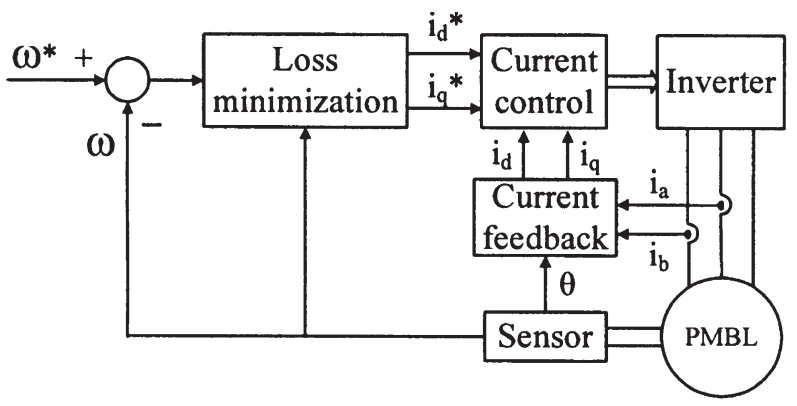

(a)

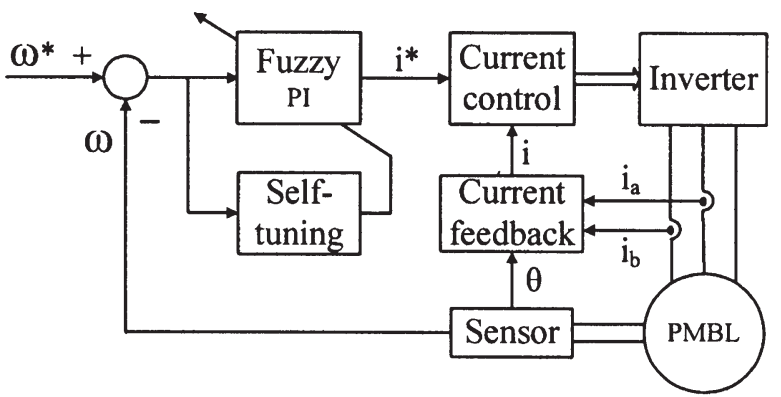

(c)

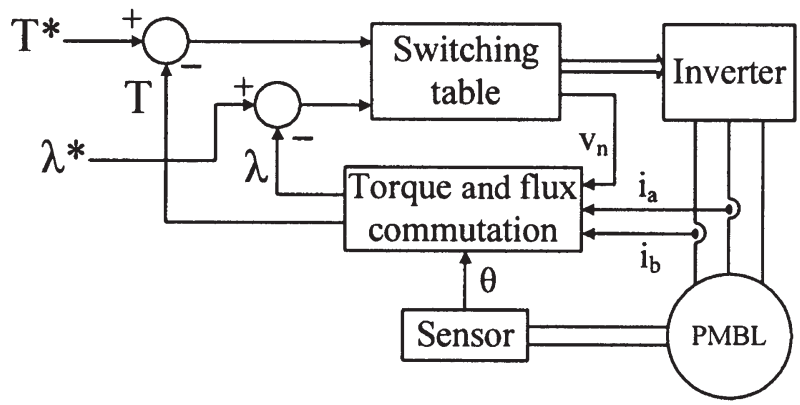

(b)

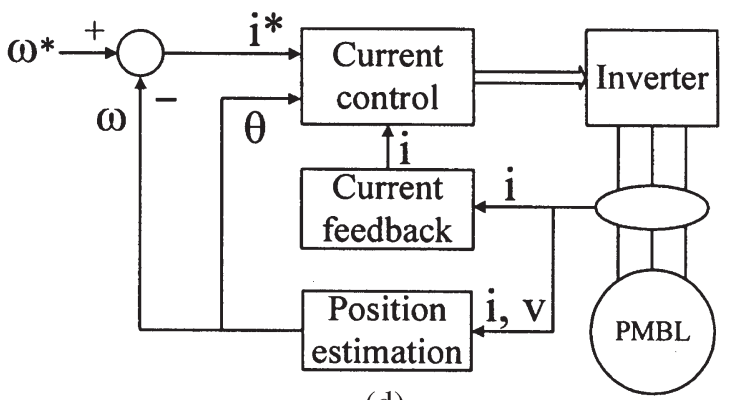

(d)

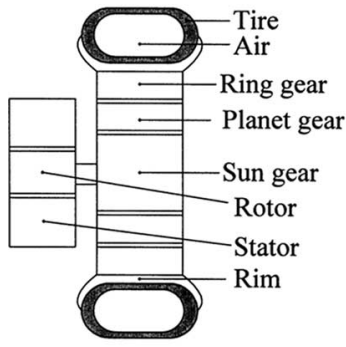

(a)

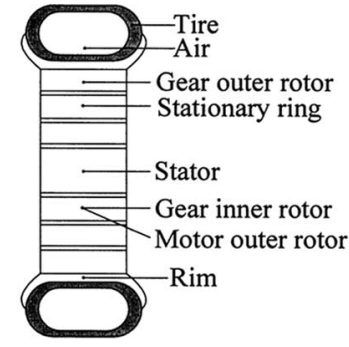

(b)

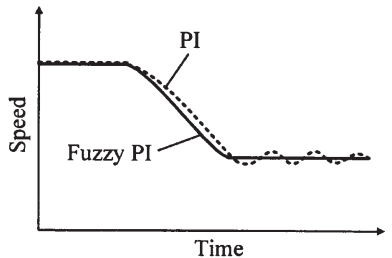

(c)

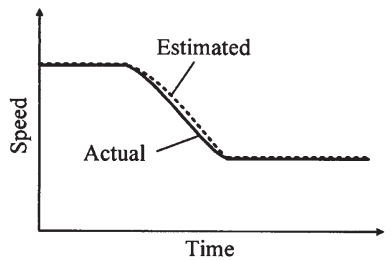

(d)
Fig. 11. Sample results of control strategies. (a) EOC. (b) DTC. (c) AIC. (d) PSC.

\section{A. Magnetic-Geared PM BL Drives}

For EVs, PM BL drives are very attractive since they inherently offer high power density and high efficiency. In particular, in-wheel PM BL drives can play the role of electronic differential [1]. As the wheel speed is only about $600 \mathrm{r} / \mathrm{min}$, the in-wheel PM BL drive is either a low-speed gearless outerrotor one or a high-speed planetary-geared inner-rotor one. Although the former one takes the advantage of gearless operation, its low-speed operation causes bulky size and heavy weight. On the other hand, although the latter one takes the merits of reduced overall size and weight, the planetary gear inevitably involves transmission loss, acoustic noise, and regular lubrication.
Fig. 12. Comparison of in-wheel drives. (a) Planetary-geared topology. (b) Magnetic-geared topology.

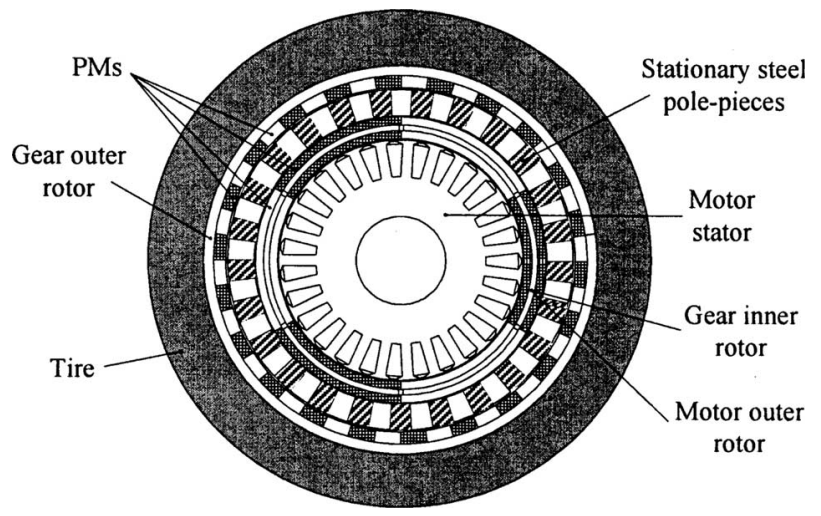

Fig. 13. Magnetic-geared PM BL drive.

Magnetic gearing is becoming attractive since it offers the advantages of high efficiency, reduced acoustic noise, and maintenance free [44]. By artfully integrating the magnetic gear into a PM BLDC drive, the low-speed requirement for direct driving and the high-speed requirement for machine design can be achieved simultaneously [45]. Fig. 12 shows 


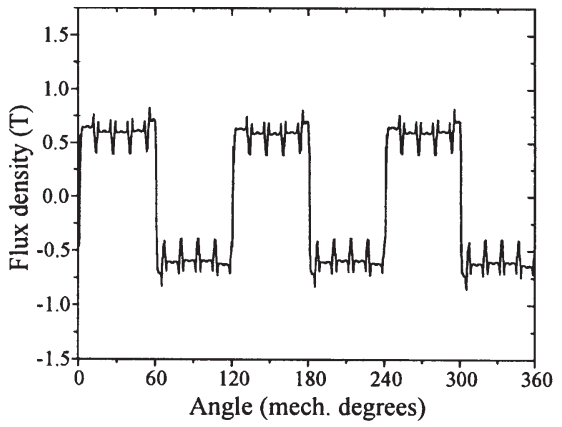

(a)

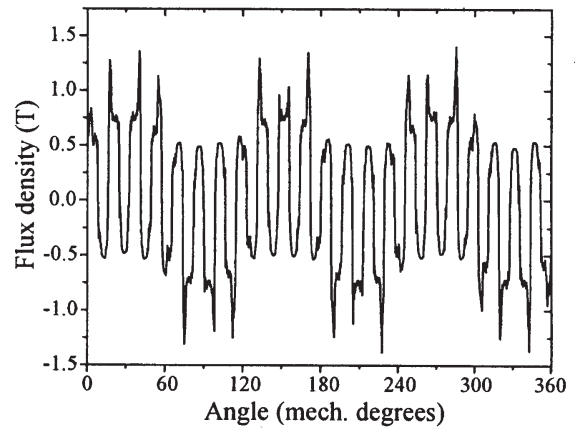

(c)

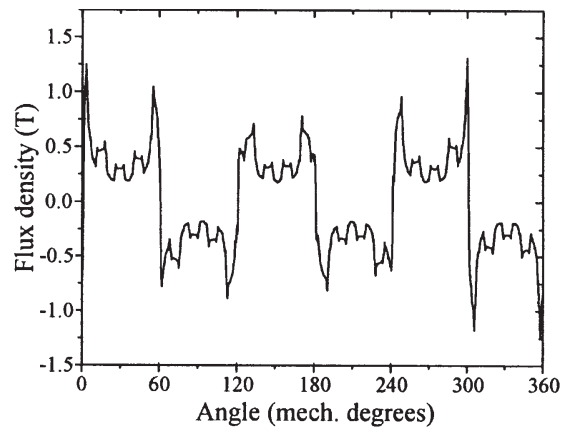

(b)

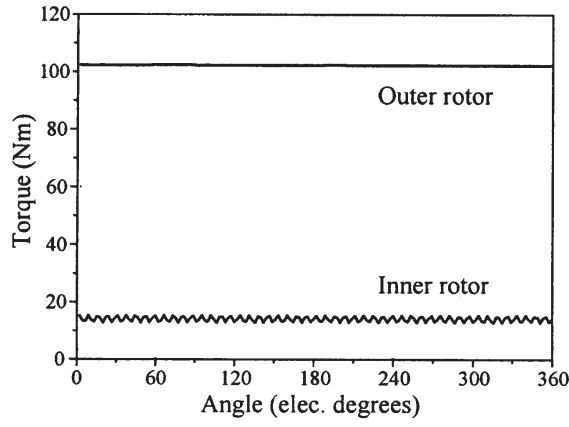

(d)

Fig. 14. Analysis of magnetic-geared PM BL drive. (a) Radial flux density in inner airgap. (b) Radial flux density in middle airgap. (c) Radial flux density in outer airgap. (d) Torques in the inner and outer rotors.

a schematic comparison of the existing planetary-gear innerrotor topology and the magnetic-geared outer-rotor topology for in-wheel drives. It can be seen that the latter topology not only offers reduced size and weight but also eliminates all the drawbacks due to the mechanical gear. Its detailed configuration is shown in Fig. 13. The artfulness is the share of a common PM rotor, namely, the outer rotor of a PM BLDC motor and the inner rotor of a concentrically arranged magnetic gear.

The operating principle of this magnetic-geared PM BLDC drive is similar to that of a high-speed planetary-geared innerrotor drive, but with the difference that this one is an outerrotor drive. That is to say, the motoring operation is the same as the PM BLDC drives. First, the stator is fed by three-phase voltages, which are rated at $220 \mathrm{~Hz}$, to achieve the rated speed of $4400 \mathrm{r} / \mathrm{min}$. Then, the magnetic gear steps down the rated speed to $600 \mathrm{r} / \mathrm{min}$, which in turn boosts up the torque for direct driving. The torque transmission is based on the modulation of the airgap-flux-density distributions along the radial and circumferential directions. By using the finite element method, it can be seen that the space harmonic is successfully modulated by the 25 stationary steel pole pieces from three pole pairs in the inner airgap to 22 pole pairs in the outer airgap, as shown in Fig. 14(a)-(c). Hence, the torque in the outer rotor can be significantly amplified to about seven times that of the inner rotor, as shown in Fig. 14(d).

\section{B. PM BL ISG Systems}

In conventional automobiles, the starter motor and generator are separately coupled with the ICE, hence providing high starting torque for cold cranking and generating electricity

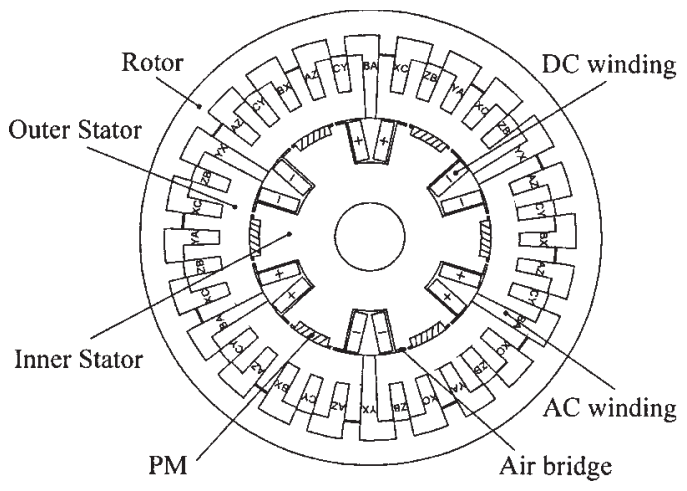

Fig. 15. PM BL ISG system.

for battery charging, respectively. This arrangement takes the advantage of simplicity but suffers from the poor utilization of both machines, hence resulting in heavy weight and bulky size. In order to incorporate both functions in a single unit, the development of integrated starter-generator (ISG) systems is accelerating.

By incorporating the inherent merits of PM BL drives into the ISG, the resulting PM BL ISG system is attractive for the latest micro- and mild HEVs. The stator doubly fed DSPM brushless machine [46] is a particular type of the aforementioned hybrid PM BL machine topologies, which is promising for application to the ISG system. Its configuration is shown in Fig. 15, in which there are two magnetic field excitations, namely, the PMs and the dc field windings, air bridges in shunt with the PMs in the inner stator, ac armature windings in the salient-pole outer stator, and the salient-pole outer rotor with no PMs or windings. 


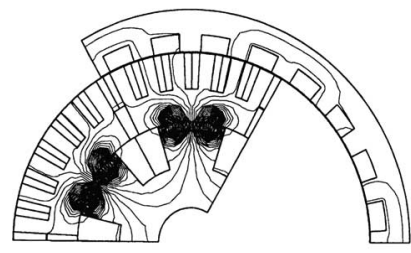

(a)

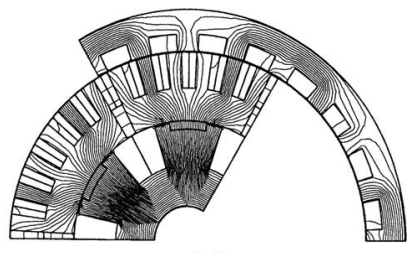

(b)
Fig. 16. Magnetic flux-density distributions under flux control. (a) Flux weakening. (b) Flux strengthening.

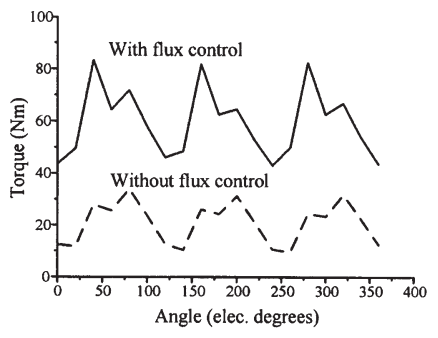

(a)

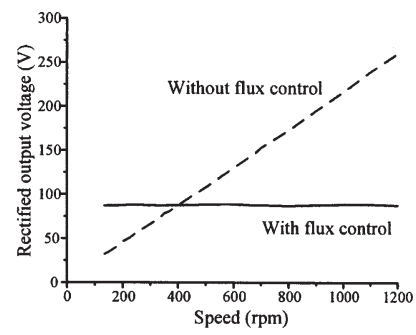

(b)
Fig. 17. Effects of flux control. (a) Torque for cold cranking. (b) Rectified output voltage for battery charging.

This stator doubly fed DSPM brushless ISG system offers several distinct advantages.

1) The dc field current can be bidirectionally controlled to strengthen and weaken the airgap flux density, hence offering high starting torque for cold cranking and constant output voltage over a wide speed range for battery charging. Meanwhile, the air bridge amplifies the effect of flux weakening.

2) The outer-rotor topology can fully utilize the space of the inner stator to accommodate the PMs and the dc field windings, hence reducing the overall size of the machine.

3) Since the outer rotor does not involve any windings or PMs, it can provide high mechanical integrity which is essential to handle the high starting torque during cold cranking.

4) Since the stator adopts fractional-slot concentrated windings, it can effectively reduce the cogging torque which usually occurs in the PM BLDC machines. In addition, it can shorten the length of end windings, hence saving the copper material and improving the power density.

The operating principle of this PM BL ISG system is similar to that of a conventional PM BLDC drive, except that the flux is controllable. Fig. 16 shows the magnetic flux-density distributions with flux weakening ( -350 A-turns) and flux strengthening (+1000 A-turns). It can be seen that the airgap flux can be effectively controlled. The developed torque waveforms with and without flux strengthening are shown in Fig. 17(a). It shows that the developed torque under flux strengthening can be boosted up by about three times, which is very essential for cold cranking. On the other hand, the no-load rectified outputvoltage characteristics with and without flux weakening are shown in Fig. 17(b). It shows that the output voltage can be maintained constant over the whole speed range, which is very essential for battery charging.

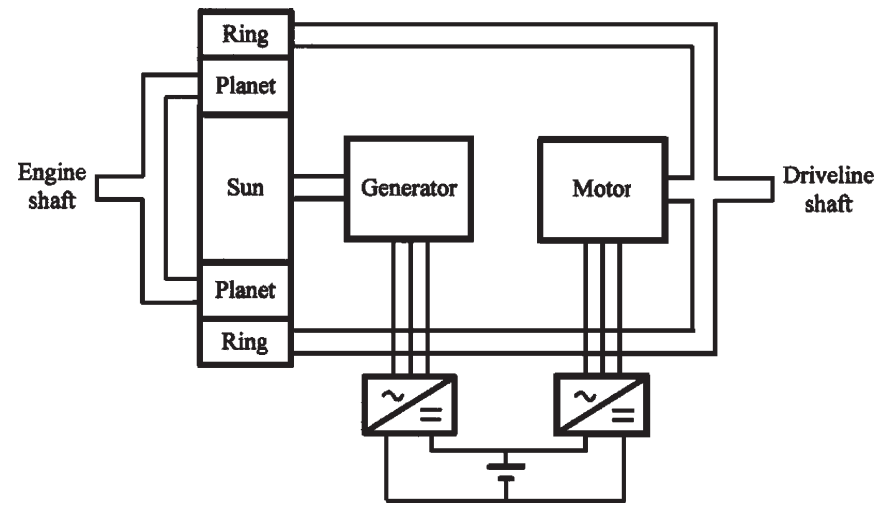

Fig. 18. Planetary-geared EVT system.

\section{PM BL EVT Systems}

In 1997, Toyota developed the first EVT system for its flagship HEV, Prius, which is a full hybrid. The schematic configuration of this EVT is shown in Fig. 18, which is mainly composed of a planetary gear, a motor, and a generator. The ICE is attached to the planet carrier, the motor is coupled with the driveline shaft so that both are attached to the ring gear, and the generator is mounted to the sun gear [47]. By controlling the power taken by the generator and then feeding back into the motor, the ICE speed can be maintained constant when the driveline-shaft speed is varying. Thus, a continuously variable ratio between the ICE speed and the wheel speed can be achieved. Hence, this EVT system takes the following advantages.

1) Because of the absence of clutches or shifting gears, it can significantly improve the transmission efficiency and reduce the overall size, hence increasing both the energy efficiency and the power density.

2) In the presence of continuously variable ratio between the ICE speed and the wheel speed, the ICE can always operate at its most energy-efficient operating point, hence resulting in a considerable reduction of fuel consumption.

3) The system can fully enable the idle stop, electric launch, regenerative braking, and full-throttle acceleration features, which are particularly essential for the full hybrids.

However, this planetary-geared EVT system inherits the fundamental drawbacks of planetary gearing, namely, transmission loss, gear noise, and need of regular lubrication.

In recent years, active research works have been conducted to eliminate this mechanical planetary gear while retaining the EVT propulsion. One viable approach is the use of concentrically arranged machines to realize power splitting for the full hybrids [48]. Fig. 19(a) shows the concentrically arranged PM BL drive to realize EVT without planetary gearing. The primary machine is a double-rotor PM BL machine, whereas the secondary machine is an outer-rotor PM BL machine. They are mechanically coupled by a common shaft and electrically connected via two power converters. When installing this PM BL EVT system in a full hybrid, it offers four modes of 


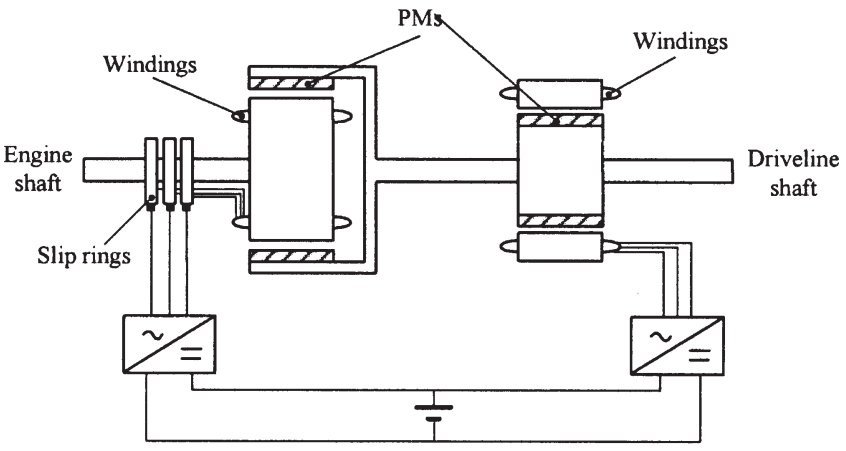

(a)

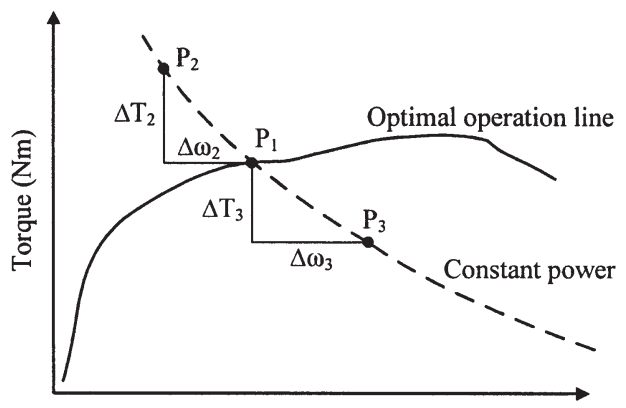

(b)

Fig. 19. Concentrically arranged PM BL EVT system. (a) Configuration. (b) Control strategy.

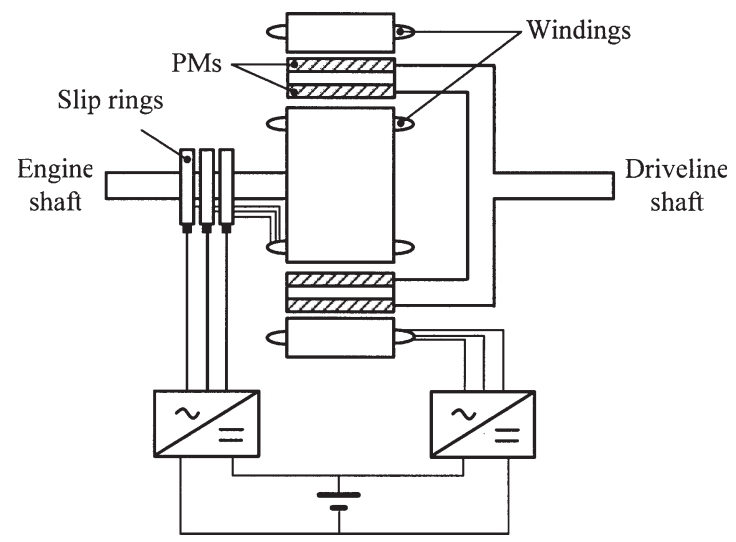

Fig. 20. Integrated PM BL EVT system.

operation, namely, cranking, charging, launching, and continuous variable transmission (CVT) [49].

1) In the cranking mode, the battery delivers the power to crank the ICE via the primary machine until the ICE reaches the speed for ignition.

2) In the charging mode, the battery is either charged by the ICE via the primary machine when the vehicle stops motion or by the secondary machine during regenerative braking.

3) In the launching mode, the battery delivers the power to launch the vehicle via the secondary machine without using the ICE.

4) In the CVT mode, the primary and secondary machines are controlled to change the speed and the torque, respectively, so that the optimal operating line of the ICE can be achieved, as shown in Fig. 19(b).
In order to reduce the system weight and size, the two machines can be integrated into a single machine. The key is to share the outer rotor of the primary machine with the rotor of the secondary machine so that the stator is placed concentrically around the outer rotor [50]. Fig. 20 shows the configuration of an integrated PM BL EVT system. The corresponding principle of operation is the same as the two concentrically arranged PM BL EVT systems. This EVT system takes the definite advantages of highly compact and lightweight. However, it still suffers from the drawbacks of slip rings and carbon brushes. It is anticipated that the development of "totally brushless" configurations for the PM BL EVT systems will be a major research direction in the field of HEVs.

\section{CONCLUSION}

In this paper, an overview of the PM BL drives for EVs and HEVs has been presented, with emphasis on machine topologies, drive operations, and control strategies. Then, three emerging research directions of the PM BL drive systems have been identified and discussed, namely, the magnetic-geared PM BL drive system for EVs, the PM BL ISG system for microand mild HEVs, and the PM BL EVT system for full HEVs. It is anticipated that the "totally brushless" configuration of the PM BL EVT systems will be a major research direction in the field of HEVs.

\section{REFERENCES}

[1] C. C. Chan and K. T. Chau, Modern Electric Vehicle Technology. Oxford, U.K.: Oxford Univ. Press, 2001.

[2] M. Ehsani, K. M. Rahman, and H. A. Toliyat, "Propulsion system design of electric and hybrid vehicles," IEEE Trans. Ind. Electron., vol. 44, no. 1, pp. 19-27, Feb. 1997.

[3] K. T. Chau and C. C. Chan, "Emerging energy-efficient technologies for hybrid electric vehicles," Proc. IEEE, vol. 95, no. 4, pp. 821-835, Apr. 2007.

[4] C. C. Chan and K. T. Chau, "An overview of power electronics in electric vehicles," IEEE Trans. Ind. Electron., vol. 44, no. 1, pp. 3-13, Feb. 1997.

[5] Z. Q. Zhu and D. Howe, "Electrical machines and drives for electric, hybrid and fuel cell vehicles," Proc. IEEE, vol. 95, no. 4, pp. 746-765, Apr. 2007.

[6] M. Terashima, T. Ashikaga, T. Mizuno, K. Natori, N. Fujiwara, and M. Yada, "Novel motors and controllers for high-performance electric vehicle with four in-wheel motors," IEEE Trans. Ind. Electron., vol. 44, no. 1, pp. 28-38, Feb. 1997.

[7] K. T. Chau and Y. S. Wong, "Hybridization of energy sources in electric vehicles," Energy Convers. Manag., vol. 42, no. 9, pp. 1059-1069, Jun. 2001.

[8] K. T. Chau and Y. S. Wong, "Overview of power management in hybrid electric vehicles," Energy Convers. Manag., vol. 43, no. 15, pp. 1953-1968, Jun. 2002.

[9] M. Ehsani, Y. Gao, S. E. Gay, and A. Emadi, Modern Electric, Hybrid Electric, and Fuel Cell Vehicles: Fundamentals, Theory, and Design. Boca Raton, FL: CRC Press, 2005.

[10] C. C. Chan, K. T. Chau, J. Z. Jiang, W. Xia, M. Zhu, and R. Zhang, "Novel permanent magnet motor drives for electric vehicles," IEEE Trans. Ind. Electron., vol. 43, no. 2, pp. 331-339, Apr. 1996.

[11] T. Wang, P. Zheng, and S. Cheng, "Design characteristics of the induction motor used for hybrid electric vehicle," IEEE Trans. Magn., vol. 41, no. 1 , pp. 505-508, Jan. 2005.

[12] W. C. Lo, C. C. Chan, Z. Q. Zhu, L. Xu, D. Howe, and K. T. Chau, "Acoustic noise radiated by PWM-controlled induction machine drives," IEEE Trans. Ind. Electron., vol. 47, no. 4, pp. 880-889, Aug. 2000.

[13] K. Yamada, K. Watanabe, T. Kodama, I. Matsuda, and T. Kobayashi, "An efficiency maximizing induction motor drive system for transmissionless electric vehicle," in Proc. Int. Electr. Vehicle Symp., 1996, pp. 529-536. 
[14] S. Z. Jiang, K. T. Chau, and C. C. Chan, "Spectral analysis of a new six-phase pole-changing induction motor drive for electric vehicles," IEEE Trans. Ind. Electron., vol. 50, no. 1, pp. 123-131, Feb. 2003.

[15] Y. J. Zhan, C. C. Chan, and K. T. Chau, "A novel sliding mode observer for indirect position sensing of switched reluctance motor drives," IEEE Trans. Ind. Electron., vol. 46, no. 2, pp. 390-397, Apr. 1999.

[16] K. M. Rahman, B. Fahimi, G. Suresh, A. V. Rajarathnam, and M. Ehsani, "Advantages of switched reluctance motor applications to EV and HEV: Design and control issues," IEEE Trans. Ind. Appl., vol. 36, no. 1, pp. 111-121, Jan./Feb. 2000.

[17] R. B. Inderka, M. Menne, and R. W. A. A. De Doncker, "Control of switched reluctance drives for electric vehicle applications," IEEE Trans. Ind. Electron., vol. 49, no. 1, pp. 48-53, Feb. 2002.

[18] S. A. Long, Z. Q. Zhu, and D. Howe, "Effectiveness of active noise and vibration cancellation for switched reluctance machines operating under alternative control strategies," IEEE Trans. Energy Convers., vol. 20, no. 4, pp. 792-801, Dec. 2005.

[19] J. Gan, K. T. Chau, C. C. Chan, and J. Z. Jiang, "A new surface-inset, permanent-magnet, brushless DC motor drive for electric vehicles," IEEE Trans. Magn., vol. 36, no. 5, pp. 3810-3818, Sep. 2000.

[20] M. Cheng, K. T. Chau, and C. C. Chan, "Static characteristics of a new doubly salient permanent magnet machine," IEEE Trans. Energy Convers., vol. 16, no. 1, pp. 20-25, Mar. 2001.

[21] M. Cheng, K. T. Chau, and C. C. Chan, "Design and analysis of a new doubly salient permanent magnet motor," IEEE Trans. Magn., vol. 37, no. 4, pp. 3012-3020, Jul. 2001.

[22] K. T. Chau, Q. Sun, Y. Fan, and M. Cheng, "Torque ripple minimization of doubly salient permanent magnet motors," IEEE Trans. Energy Convers., vol. 20, no. 2, pp. 352-358, Jun. 2005.

[23] R. P. Deodhar, S. Andersson, I. Boldea, and T. J. E. Miller, "The flux-reversal machine: A new brushless doubly-salient permanent magnet machine," IEEE Trans. Ind. Appl., vol. 33, no. 4, pp. 925-934, Jul./Aug. 1997.

[24] Z. Q. Zhu, Y. Pang, D. Howe, S. Iwasaki, R. Deodhar, and A. Pride, "Analysis of electromagnetic performance of flux-switching permanent magnet machines by non-linear adaptive lumped parameter magnetic circuit model," IEEE Trans. Magn., vol. 41, no. 11, pp. 4277-4287, Nov. 2005.

[25] K. T. Chau, J. Z. Jiang, and Y. Wang, "A novel stator doubly fed doubly salient permanent magnet brushless machine," IEEE Trans. Magn., vol. 39, no. 5, pp. 3001-3003, Sep. 2003.

[26] K. T. Chau, Y. B. Li, J. Z. Jiang, and S. Niu, "Design and control of a PM brushless hybrid generator for wind power application," IEEE Trans. Magn., vol. 42, no. 10, pp. 3497-3499, Oct. 2006.

[27] V. Ostovic, "Memory motor," IEEE Ind. Appl. Mag., vol. 9, no. 1, pp. 52-61, Jan./Feb. 2003.

[28] W. L. Soong and N. Ertugrul, "Field-weakening performance of interior permanent-magnet motors," IEEE Trans. Ind. Appl., vol. 38, no. 5, pp. 1251-1258, Sep./Oct. 2002.

[29] Z. Q. Zhu, Y. S. Chen, and D. Howe, "On-line optimal field weakening control of permanent magnet brushless AC drives," IEEE Trans. Ind. Appl., vol. 36, no. 6, pp. 1661-1668, Nov./Dec. 2000.

[30] M. N. Uddin and M. A. Rahman, "High-speed control of IPMSM drives using improved fuzzy logic algorithms," IEEE Trans. Ind. Electron., vol. 54, no. 1, pp. 190-199, Feb. 2007.

[31] C. C. Chan, J. Z. Jiang, W. Xia, and K. T. Chau, "Novel wide range speed control of permanent magnet brushless motor drives," IEEE Trans. Power Electron., vol. 10, no. 5, pp. 539-546, Sep. 1995.

[32] Y. Kim, Y. Kook, and Y. Ko, "A new technique of reducing torque ripples for BDCM drives," IEEE Trans. Ind. Electron., vol. 44, no. 5, pp. 735-739, Oct. 1997.

[33] Y. Wang, K. T. Chau, C. C. Chan, and J. Z. Jiang, "Design and analysis of a new multiphase polygonal-winding permanent-magnet brushless DC machine," IEEE Trans. Magn., vol. 38, no. 5, pp. 3258-3260, Sep. 2002.

[34] M. Cheng, K. T. Chau, and C. C. Chan, "New split-winding doubly salient permanent magnet motor drive," IEEE Trans. Aerosp. Electron. Syst., vol. 39, no. 1, pp. 202-210, Jan. 2003.

[35] C. C. Chan and K. T. Chau, "An advanced permanent magnet motor drive system for battery-powered electric vehicles," IEEE Trans. Veh. Technol., vol. 45, no. 1, pp. 180-188, Feb. 1996.

[36] C. Cavallaro, A. O. D. Tommaso, R. Miceli, A. Raciti, G. R. Galluzzo, and M. Trapanese, "Efficiency enhancement of permanent-magnet synchronous motor drives by online loss minimization approaches," IEEE Trans. Ind. Electron., vol. 52, no. 4, pp. 1153-1160, Aug. 2005.
[37] M. F. Rahman, M. E. Haque, L. Tang, and L. Zhong, "Problems associated with the direct torque control of an interior permanent-magnet synchronous motor drive and their remedies," IEEE Trans. Ind. Electron., vol. 51, no. 4, pp. 799-809, Aug. 2004.

[38] M. Pascas and J. Weber, "Predictive direct torque control for the PM synchronous machine," IEEE Trans. Ind. Electron., vol. 52, no. 5, pp. 1350-1356, Oct. 2005.

[39] M. Cheng, Q. Sun, and E. Zhou, "New self-tuning fuzzy PI control of a novel doubly salient permanent-magnet motor drive," IEEE Trans. Ind. Electron., vol. 53, no. 3, pp. 814-821, Jun. 2006.

[40] T. Pajchrowski and K. Zawirski, "Application of artificial neural network to robust speed control of servodrive," IEEE Trans. Ind. Electron., vol. 54, no. 1, pp. 200-207, Feb. 2007.

[41] P. P. Acarnley and J. F. Watson, "Review of position-sensorless operation of brushless permanent-magnet machines," IEEE Trans. Ind. Electron., vol. 53, no. 2, pp. 352-362, Apr. 2006.

[42] C. Silva, G. M. Asher, and M. Sumner, "Hybrid rotor position observer for wide speed-range sensorless PM motor drives including zero speed," IEEE Trans. Ind. Electron., vol. 53, no. 2, pp. 373-378, Apr. 2006.

[43] C. D. Angelo, G. Bossio, J. Solsona, G. O. Garcia, and M. I. Valla, "Mechanical sensorless speed control of permanent-magnet AC motors driving an unknown load," IEEE Trans. Ind. Electron., vol. 53, no. 2, pp. 406-414, Apr. 2006.

[44] K. Atallah and D. Howe, "A novel high performance magnetic gear," IEEE Trans. Magn., vol. 37, no. 4, pp. 2844-2846, Jul. 2001.

[45] K. T. Chau, D. Zhang, J. Z. Jiang, C. Liu, and Y. Zhang, "Design of a magnetic-geared outer-rotor permanent-magnet brushless motor for electric vehicles," IEEE Trans. Magn., vol. 43, no. 6, pp. 2504-2506, Jun. 2007.

[46] K. T. Chau, Y. B. Li, J. Z. Jiang, and C. Liu, "Design and analysis of a stator doubly fed doubly salient permanent magnet machine for automotive engines," IEEE Trans. Magn., vol. 42, no. 10, pp. 3470-3472, Oct. 2006.

[47] J. M. Miller, "Hybrid electric vehicle propulsion system architectures of the e-CVT type," IEEE Trans. Power Electron., vol. 21, no. 3, pp. 756-767, May 2006.

[48] S. Eriksson and C. Sadarangani, "A four-quadrant HEV drive system," in Proc. IEEE Veh. Technol. Conf., Sep. 2002, pp. 1510-1514.

[49] Y. Cheng, S. Cui, L. Song, and C. C. Chan, "The study of the operation modes and control strategies of an advanced electromechanical converter for automobiles," IEEE Trans. Magn., vol. 43, no. 1, pp. 430-433, Jan. 2007.

[50] M. J. Hoeijmakers and J. A. Ferreira, "The electric variable transmission," IEEE Trans. Ind. Appl., vol. 42, no. 4, pp. 1092-1100, Jul./Aug. 2006.

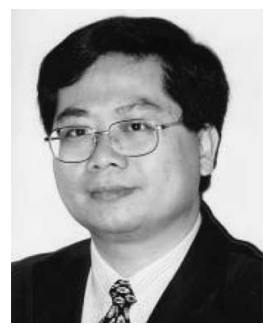

K. T. Chau (M'89-SM'04) received the B.Sc.(Eng.) (first-class honors), M.Phil., and Ph.D. degrees in electrical and electronic engineering from The University of Hong Kong, Hong Kong, China, in 1988, 1991, and 1993, respectively.

He is currently a Professor with the Department of Electrical and Electronic Engineering and the Director of the International Research Center for Electric Vehicles, The University of Hong Kong. His teaching and research interests focus on three main areas: electric vehicles, electric drives, and power electronics. In these areas, he has published over 200 refereed technical papers. $\mathrm{He}$ is also the coauthor of a monograph Modern Electric Vehicle Technology (Oxford University Press, 2001).

Dr. Chau is a Fellow of the Institution of Engineering and Technology. He was the recipient of the Outstanding Young Researcher Award in 2003, the University Teaching Fellowship Award in 2004, and the Award for Innovative Excellence in Teaching, Learning, and Technology in 2005. 


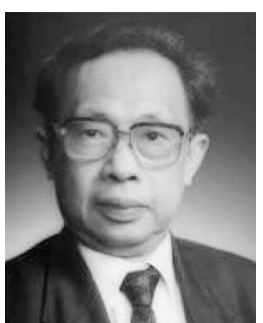

C. C. Chan (M'77-SM'77-F'92).

He has had over ten years of industrial experience and over 35 years of academic experience. He is currently the Honorary Professor and the Former Head of the International Research Center for Electric Vehicles, Department of Electrical and Electronic Engineering, The University of Hong Kong, Hong Kong, China. He is the Founding President of the International Academy for Advanced Study, China, the Cofounder and the Rotating President of the World Electric Vehicle Association, and the President of the Electric Vehicles Association of the Asia Pacific. He serves as a Senior Advisor to governments, academic institutions, and leading industries worldwide.

Dr. Chan is a Fellow of the Royal Academy of Engineering, U.K., the Chinese Academy of Engineering, The Ukraine Academy of Engineering Sciences, the Institution of Electrical Engineers (IEE), and the Hong Kong Institution of Engineers. He has delivered lectures on electric vehicles worldwide. He was named BFather of Asian Electric Vehicles by the magazine Global View in 2002. He was also named BPitamaha (Grandfather) of Electric Vehicle Technology in India at the IEEE Conference on Electric and Hybrid Vehicles in 2006. He received the IEE International Lecture Medal in 2000.

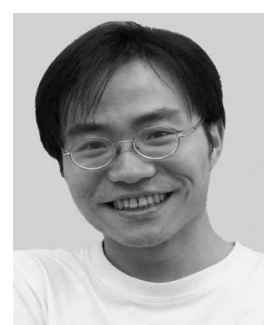

Chunhua Liu (S'05) received the B.Eng. and M.Eng. degrees from the Department of Automatic Control, Beijing Institute of Technology, Beijing, China, in 2002 and 2005, respectively. He is currently working toward the Ph.D. degree in electrical and electronic engineering in the International Research Center for Electric Vehicles, Department of Electrical and Electronic Engineering, The University of Hong Kong, Hong Kong, China.

His research interests are the areas of electric drives, electric vehicles (EVs), and power electronics. He currently focuses on the design of permanent-magnet brushless motors and magnetic gears, as well as various integrated starter-generator systems and electric variable-transmission systems for hybrid EVs. 